\title{
FAKTOR-FAKTOR YANG MEMPENGARUHI HASIL PRODUKSI UNIT PENANGKAPAN PUKAT CINCIN DI PPN SIBOLGA, SUMATERA UTARA
}

\author{
Factor Affecing The Production of Purse Seine Unit in Fishing Base Sibolga Fishing Port, North \\ Sumatera
}

Oleh:

\author{
Irwan Limbong $^{1 *}$, Eko Sri Wiyono², Roza Yusfiandayani ${ }^{2}$ \\ ${ }^{1}$ Mahasiswa Program Pascasarjana Departemen PSP FPIK IPB \\ ${ }^{2}$ Departemen PSP FPIK IPB \\ *Korespondensi: irwanlimbong45@gmail.com
}

\begin{abstract}
ABSTRAK
Perairan Sibolga secara geografis cukup strategis, karena terletak di Samudera Hindia, hasil penangkapannya kebanyakan didaratkan di Pelabuhan Perikanan Sibolga. Salah satu alat tangkap yang sangat produktif di Sibolga adalah pukat cincin dari tahun ketahun meningkatkan jumlah armada unit penangkapan yang berdampak kepada over ekspoitasi pada tahun 2015. Berdasarkan hal tersebut dijalankan peraturan mengenai pembatasan unit armada alat tangkap pukat cincin dan meningkatkan hasil tangkapan ikan secara bertahap. Efisiensi penggunaan armada kapal penangkapan ikan yang menggunakan alat tanggkap pukat cincin sangat terkait dengan masalah identifikasi faktor-faktor produksi yang mempengaruhi produktivitas dan efektifitas dalam memanfaatkan sumberdaya ikan dilakuan pengkajian tentang faktor produksi agar mengetahui faktor-faktor apa saja yang mempengaruhi hasil tangkapan guna meningkatkan hasil tangkapan nelayan. Metode yang digunakan dalam penelitian ini adalah setudi kasus dengan analisis deskriptif dengan metode pengambilan sampel purposive sampling. Metode analisis yang digunakan berupa uji asumsi klasik dan fungsi produksi Cobb-Douglas. Hasil penelitian menunjukkan bahwa faktor-faktor yang berperan nyata pada unit alat tangkap pukat cincin di PPN Sibolga yaitu ukuran kapal (X1), daya mesin kapal (X3), panjang jaring (X3), dan tinggi jaring (X4). Hubungan antara faktor-faktor produksi alat tangkap pukat cincin di PPN Sibolga dapat di presentasikan dalam model fungsi Cobb-Douglas, yaitu sebagai berikut: $\operatorname{LnY}=-$ 7.034.574 + 21.254 LnX1 + 6.241 LnX2 + 2.369 LnX3 + 54.410 LnX4.
\end{abstract}

Kata kunci: pukat cincin, faktor produksi, PPN Sibolga

\begin{abstract}
Sibolga's water is geographically quaite srategic, because it located Indian Ocean, mostly the result of it's arrest landed at fishing Sibolga Fishing Port. One of the most productive gear is Sibolga the purse seine which every year increase the number of arrests that impact fleet units to over exploitation in 2015. To overcome the issue, the regulation on Purse seine fleets restrictions was reapplied control the increase of fishing fleets and increase fish catches gradually. The efficiency of purse seine fishing fleets usage was strogly related to the identifying issues of production factors influencing the productivity and effectiveness of fish resource utilization. Therefore, it was necessary to identifed the production factors in order to determine fishing increasing factors eventually to improve the fishermen's captured. The method in this research was descriptive case study with purposive sampling technique. The analysing method was classical assumption test and the production function of Cobb-Douglas. The results showed that factors significant in fishing production purse seine in Sibolga Fishing Port, measure of the vessel (X1), power boat engines (X2), nets of length (X3), high net (X4). The relationship between the factors of production to the production of purse seine fishing
\end{abstract}


gear in Sibolga Fishing Port can be represented in the model of the Cobb-Douglas functuon, namely as follows; $\operatorname{Ln} Y=-7.034 .574+21.254 \operatorname{LnX} 1+6.241 \operatorname{LnX} 2+2.369 \operatorname{LnX} 3+54.410 \operatorname{LnX} 4$.

Keywords: purse seine, factors of pruction, sibolga

\section{PENDAHULUAN}

Pantai Barat Pulau Sumatera memiliki potensi perikanan yang sangat besar, baik di perairan teritorial maupun di perairan zona ekonomi eksklusif hingga sejauh 200 mill dari pantai. Potensi yang besar tersebut membuat usaha perikanan khususnya usaha penangkapan ikan di pantai Barat Sumatera lebih besar pula dibandingkan pantai Timurnya.

Perkembangan usaha perikanan laut yang menggunakan kapal Pukat cincin yang mendaratkan hasil tangkapannya di PPN Sibolga pada dasarnya berusaha meningkatkan hasil tangkapan dengan tujuan untuk memperbesar pendapatan untuk memenuhi kebutuhan hidupnya. Menurut Satria (2009), nelayan sebagai usahawan harus pandai memanfaatkan segala faktor-faktor yang berhubungan dengan kegiatan ekonomi.

Keberhasilan penangkapan sangat dipengaruhi oleh tingkat upaya penangkapan yang dilakukan oleh nelayan pukat cincin dalam penggunaan faktor-faktor produksi. $M c^{-}$ Cluskey dan Lewison (2008) menyatakan bahwa upaya penangkapan merupakan ukuran untuk menghasilkan sejumlah hasil tangkapan atau ukuran produktivitas dari unit penangkapan ikan. Setiap armada pukat cincin di PPN Sibolga memiliki keragaman faktor produksi yang tentunya akan berpengaruh terhadap produksi yang dihasilkan. Hal ini diduga menyebabkan banyak dari para nelayan terus meningkatkan penggunaan faktor-faktor produksi tersebut tanpa memperhatikan tingkat efisiensi dari faktor tersebut.

Doll and Orazen dalam Soekartawi (1994) menggambarkan fungsi produksi sebagai hubungan antara input dan output sehingga menghasilkan produk tertentu dengan kata lain fungsi produksi menggambarkan kombinasi penggunaan beberapa faktor produksi unuk menghasilkan satu tingkat produksi tertentu.
Tujuan dari penelitian ini adalah mengkaji tentang faktor produksi untuk mengetahui faktor-fakor apa saja yang mempengaruhi hasil tangkapan dan meningkatkan penghasilan nelayan dan mengkaji keragaan teknis unit penangkapan pukat cincin di PPN Sibolga. Terdapat beberapa faktor produksi yang dapat mempengaruhi produksi hasil tangkapan. Berdasarkan penelitian yang dilakukan oleh Muhktar (2008), menganalisis mengenai faktor-fator yang mempengaruhi produksi di kapal pukat cincin di Pelabuhan Perikanan Samudera Kendari. Penelitian tersebut terdapat tujuh variabel faktor produksi yang diduga berpengaruh terhadap hasil produksi yaitu ukuran kapal (GT), kekuatan mesin (PK), konsumsi bahan bakar minyak (L), panjang jaring (m), dalam jaring (m), jumlah ABK (orang) dan jumlah lampu (unit). Sedangkan penelitian yang lain yang dilakukan oleh Kusiani (2013), menganalisis faktor-faktor produksi pukat cincin di Kabupaten Gorontalo dalam penelitian ini terdapat satu yang berpengaruh terhadap hasil tangkapan ikan oleh nelayan adalah panjang pukat cincin. Dalam penelitian ini faktor-faktor yang akan dikaji sebagai variabel yang diduga mempengaruhi hasil tangkapan pukat cincin meliputi variabel ukuran kapal (GT), daya mesin kapal (HP), panjang jaring pukat cincin (m), tinggi jaring pukat cincin (m), jumlah awak kapal (orang), bahan bakar minyak (liter), jumlah lampu (unit), Jumlah es (balok), air tawar (liter), perbekalan (rupiah).

\section{METODE PENELITIAN}

Penelitian ini dilaksanakan di Pelabuhan Perikanan Nusantara (PPN) Sibolga basis pukat cincin, Kota Sibolga Provinsi Sumatera Utara Pengamatan dan pengumpulan data dilakukan selama dua bulan yaitu dari bulan Juli sampai Agustus 2016.

Metode pengambilan sampel menggunakan metode purposive sampling diperoleh sampel 20 unit alat tangkap pukat cincin. 
Metode pengumpulan data dilakukan dengan survei,wawancara, dokumentasi dan studi pustaka. Data primer meliputi data primer diperoleh berupa faktor-faktor produksi unit penangkapan pukat cincin yaitu ukuran kapal, daya mesin kapal, panjang jaring, tinggi jaring, tinggi jaring, jumlah awak kapal, BBM, jumlah lampu, jumlah es, jumlah air tawar dan biaya perbekalan yang digunakan setiap satu trip melaut pada unit penangkapan pukat cincin harian selama sebulan penelitian berlangsung. Data sekunder diperoleh dari Statistik Pelabuhan Perikanan Nusantara Sibolga

Analisis yang digunakan adalah uji asumsi klasik (uji normalitas, uji heteroskedastisitas, uji autokorelasi, uji multikolinearitas) dan fungsi produksi CobbDouglas. Uji asumsi klasik digunakan untuk mengetahui data tersebar normal atau tidak dan untuk mengetahui faktor produksi yang paling berpengaruh terhadap produksi. Fungsi produksi Cobb-Douglas dilakukan untuk mengisimasi hubungan antara produksi dan faktor-faktor produksi dengan persamaan $\ln \mathrm{Y}$ $=\ln \mathrm{a}+\mathrm{b}_{1} \ln \mathrm{X}_{1}+\mathrm{b}_{2} \ln \mathrm{X}_{2}+\mathrm{e}$.

Penggunaan pengaruh faktor-faktor terhadap produksi diuji hipotesis, yaitu dengan menggunakan uji statistik berupa pengujian pengaruh bersama-bersama faktor produksi $(\mathrm{Y})$ yang dilakukan dengan uji $\mathrm{F}$, yaitu :

- $\mathrm{H}_{\mathrm{o}}: b_{\mathrm{i}}=0($ untuk $\mathrm{i}=1,2,3, \ldots, \mathrm{n})$,
Berarti peubah $\mathrm{X}_{\mathrm{i}}$ tidak mem-
berikan pengaruh yang nyata
terhadap peubah $\mathrm{Y}$.

- $\quad H_{i}$ : Minimal salah satu $b_{i} \neq 0$ (untuk $\mathrm{i}=1,2,3, \ldots, \mathrm{n})$, Berarti peubah $\mathrm{X}_{\mathrm{i}}$ memberikan pengaruh yang nyata terhadap peubah Y.

Sehingga :

$$
\begin{aligned}
& \text { Jika } \mathrm{F}_{\text {hitung }}>\mathrm{F}_{\text {tabel }}=\text { tolak } \mathrm{H}_{\circ} \\
& \mathrm{F}_{\text {hitung }}<\mathrm{F}_{\text {tabel }}=\text { gagal tolak } \mathrm{H}_{\circ}
\end{aligned}
$$

Keterangan :

- Tolak $H_{0}$, artinya dengan selang kepercayaan tertentu faktor produksi $\left(\mathrm{X}_{\mathrm{i}}\right)$ yang digunakan memiliki pengaruh nyata terhadap perubahan produksi (Y) unit penangkapan pukat cincin.

- Gagal tolak $\mathrm{H}_{\mathrm{o}}$, artinya dengan selang kepercayaan tertentu faktor produksi $\left(\mathrm{X}_{\mathrm{i}}\right)$ yang digunakan tidak memilikki pengaruh nyata terhadap perubah produksi (Yi) penangkapan pukat cincin.

\section{HASIL DAN PEMBAHASAN}

\section{Potensi Perikanan Pukat Cincin}

Berdasarkan Tabel 1 dapet dilihat bahwa jenis alat tangkap pukat cincin mencapai 197 ditahun 2009 kemudian mengalami peningkatan hingga 215 di tahun 2015.

Terdapat dua pembagian musim pada proses penangkapan di Sibolga, Sumatera Utara. Pembagian Musim tersebut yaitu musim biasa berkisar April sampai September dan musim puncak yaitu Oktober sampai Maret. Jumlah trip dalam satu bulan yaitu 15 trip,

Tabel 1 Jumlah alat tangkap di PPN Sibolga 2009 - 2015

\begin{tabular}{lcccc}
\hline \multirow{2}{*}{ Tahun } & \multicolumn{4}{c}{ Alat tangkap } \\
\cline { 2 - 5 } & Pukat Cincin & Bagan Apung & Gill Net & Pancing \\
\hline 2009 & 197 & 75 & 107 & 19 \\
2010 & 205 & 76 & 112 & 20 \\
2011 & 205 & 78 & 112 & 20 \\
2012 & 203 & 91 & 146 & 26 \\
2013 & 207 & 98 & 145 & 22 \\
2014 & 212 & 100 & 132 & 24 \\
2015 & 215 & 88 & 142 & 21
\end{tabular}

Sumber: PPN Sibolga (2015) 
Tabel 2 Jumlah produksi ikan Tahun 2015 Di Pelabuhan PPN Sibolga

\begin{tabular}{llcc}
\hline No & Bulan & Jumlah Produksi (Kg) & Nilai Produksi \\
\hline 1 & Januari & 166.739 & 7.503 .255 .000 \\
2 & Februari & 103.894 & 4.675 .230 .000 \\
3 & Maret & 144.672 & 6.510 .240 .000 \\
4 & April & 88.768 & 3.994 .560 .000 \\
5 & Mei & 96.708 & 4.351 .860 .000 \\
6 & Juni & 102.759 & 4.624 .155 .000 \\
7 & Juli & 159.570 & 7.180 .650 .000 \\
8 & Agustus & 149.370 & 6.721 .650 .000 \\
9 & September & 172.910 & 7.780 .950 .000 \\
10 & Oktober & 194.285 & 8.742 .825 .000 \\
11 & November & 161.720 & 7.277 .400 .000 \\
12 & Desember & 131.997 & 5.939 .865 .000 \\
\hline
\end{tabular}

Sumber: PPN Sibolga (2015)

tersisa 10 hari yang biasa digunakan untuk memperbaiki jaring yang rusak dikarenakan disaat yang bersamaan sedang terjadi terang bulan menyebabkan hasil tangkapan kurang maksimal jika tetap dilakukan proses penangkapan.

Penentuan daerah penangkapan ikan di Sibolga masih menggunakan cara tradisonal yaitu berdasarkan naluri atau pengalaman yang sudah turun menurun dan juga melihat kondisi perairan. Penentuan daerah penangkapan ikan di tentukan juga dengan dipengaruhi juga oleh keadaan bulan, hujan, dan musim. jika sedang terjadi musim barat, cuaca sangat kurang bersahabat yang tingginya gelombang perairan luar. sehingga nelayan lebih memilih melakukan kegiatan pengoperasian alat tangkap di dekat pulau yang arusnya lebih tenang dan tidak bergelombang. Nelayan alat tangkap pukat cincin Sibolga melakukan penangkapan ikan tepatnya di perairan Nias dimana waktu tempuhnya fishing base menuju fishing ground sekitar 9 jam. Pada saat musim angin timur kondisi cuaca dan perairan lebih tenang, sehingga nelayan alat tangkap pukat cincin memilih untuk melakukan penangkapan di perairan luar Samudera Hindia.
Berdasarkan Tabel 2, produksi perikanan pukat cincin pada tahun 2015, produksi tertinggi terjadi pada bulan Oktober yaitu sebesar $194.285 \mathrm{~kg} /$ bulan dengan nilai produksi sebesar Rp. 8.742.825.000. jumlah produksi terendah terjadi pada bulan April $88.768 \mathrm{~kg} /$ bulan dengan nilai produksi Rp. 3.994.560.000. Jenis ikan yang didaratkan di PPN Sibolga di antaranya kelompok pelagis kecil, pelagis besar, dan damersal. jumlah produksi tiap bulannya selalu berubah - ubah bergantung pada musim ikan, jumlah armada penangkapan yang melakukan operasi penangkapan dan jumlah trip penangkapan dilakukan nelayan.

\section{Keragaan Alat Tangkap Pukat Cincin di PPN Sibolga}

Berdasarkan pengukuran yang telah dilakukan, umumnya alat tangkap pukat cincin terdiri dai badan jaring, kantong, selvedge, pelampung, pemberat, tali ris atas, talu ris bawah, tali kerut dan cincin, panjang rata-rata alat tangkap jaring pukat cincin yaitu 600 meter. Bentuk kontruksi alat tangkap ini adalah trapesium. Tali ris atas terdiri dari tali pelampung tali penguat ris atas, sedangkam tali ris bawah terdiri dari tali pemberat dan tali penguat ris bawah. Bagian kantong pada alat tangkap ini terbagi menjadi 3 bagian. Letak 
Tabel 3 Bagian-bagian alat tangkap pukat cincin di PPN Sibolga

\begin{tabular}{llll}
\hline No & \multicolumn{1}{c}{ Parameter } & Uraian \\
\hline 1 & Alat tangkap & \\
& $\begin{array}{l}\text { a. Panjang jaring } \\
\text { b. Tinggi jaring }\end{array}$ & $140-600$ meter \\
& $50-83$ meter \\
2 & Kapal & $58-117 \mathrm{GT}$ \\
& $\begin{array}{l}\text { a. Ukuran kapal } \\
\text { b. Tenaga penggerak }\end{array}$ & $140-600 \mathrm{HP}$ \\
3 & Anak buah Kapal & $12-20$ orang \\
4 & Alat bantu penangkapan & $14-19$ Unit Lampu \\
5 & Metode penangkapan & \\
& a. Waktu & $22.00-01.00$ \\
& b. Teknik & Aktif dan Pasif ( menetap dan berpindah fishing ground) \\
7 & Daerah penangkapan & 9 - 10 (Nias)
\end{tabular}

Sumber: Penelitian (2016)

kantongnya berada di pinggir alat tangkap. Tinggi jaring ini mencapai 83 meter. Ukuran mata jaring 2 inchi.

Jenis bahan bahan alat bahan ini adalah PA (polyamide) untuk bagian jaringnya, tali-temali berjenis bahan PE (polyethylene), bahan pelampungnya adalah PVC (polyvynil chloride), pemberat bahannya timah hitam berbentuk lonjong, dan cincinnya terbuat dari stainless. Pelampung tanda berbentuk lonjong dengan jumlah 2 buah.

Kapal pukat cincin di Sibolga memiliki panjang keseluruhan 23,83 meter. Lebar 7,70 meter dan depth (dalam) 2,10 meter. Terbuat dari material kayu serta terdapat 3 jenis mesin, yaitu : mesin penggerak, mesin gardan, dan mesin alat bantu kapal. Mesin penggerak pukat cincin merek Nisan $600 \mathrm{Hp}$ dan mesin alat bantu lampu dengan merek mitsubisihbahan bakar solar.

Nelayan pukat cincin di Sibolga adalah nelayan buruh. Nelayan buruh adalah nelayan yang bekerja sebagai ABK atau juragan kepada pemilik kapal. Nelayan pukat cincin Sibolga terdiri dari 20 orang. Dengan terdiri 19 adalah bagian dari ABK dan 1 juragan. Juragan adalah penentu peran tempat fishing ground melihat dari bagian atas kapal.
Nelayan pukat cincin dalam pembagian keuntungan menggunakan sistem bagi hasil dimana total keseluruhan hasil pada hari itu dikurangi biaya perbekalan kemudian sisanya dibagikan ke nelayan dengan kesepakatan yaitu ABK dan juragan mendapatkan 50\% dan pemilik kapal 50\%. Pembagian hasil kepada juragan di berikan $10 \%$ dari $50 \%$, kemudian sisanya dibagi rata kepada seluruh ABK.

Unit penangkapan pukat cincin di PPN Sibolga sangat bergantung terhadap alat bantu penangkapan ikan. Alat bantu penangkapan ikan yang digunakan antara lain gardan dan lampu. Alat bantu gardan yang diguunakan yaitu berasal gardan truk yang sudah tidak dipakai, fungsiny adalah untuk menarik tali kerut jaring pukat cincin. Alat bantu gardan penggerak mesin bermerek Yanmar dengan kekuatan 180 PK.

Lampu merupakan alat bantu penangkapaan pukat cincin di PPN Sibolga dengan jumlah 14 unit. Jenis lampu tersebut yaitu lampu galaksi dan lampu neon. Dalam satu unit penangkapan penangkapan pukat cincin di PPN Sibolga terdapat 8 unit lampu galaksi , 4 unit lampu neon. Adapun fungsi setiap lampu tersendiri adalah : 
1. Lampu galaksi berfungsi sebagai lampu pencari ikan dan untuk mempengaruhi ikan yang berada jauh dari kapal

2. Lampu neon berfungsi sebagai untuk memikat ikan supaya tetap bertahan berkumpul disekitar kapal.

Metode pengoperasian pukat cincin di PPN Sibolga adalah sebagai berikut :

1. Sebelum melakukan kegiatan penangkapan, para nelayan terlebih dahulu mempersiapkan segala kebutuhan yang diperlukan selama operasi penangkapan mulai berangkat dari fishing base menuju fishing ground

2. Pencarian melaului naluri ataupun pengalaman, umumnya dapat menduga dan daerah penangkapan. Adanya gerombolan ikan di pengaruhi keadaan bulan, hujan, musim, dan arah angin.

3. Penurunan bagian alat tangkap (setting) dimulai dari bagian belakang buritan kapal tali pelampung tanda di lepas dari tumpukan jaring keperairan hingga mengapung dipermukaan perairan.

4. Pengangkatan (hauling) dilakukan tali pengait dilemparkan unuk mengambil tali selembar kanan an tali kerut. Gardan sebagai penarik tali seembar pelampung dan tali penggerut pada proses hauling alat tangkap berlansung
Kontruksi dari penangkapan pukat cincin di PPN Sibolga target utamanya adalah ikan pelagis besar dan pelagis kecil. Jenis-jenis hasil tangkapan puat cincin yaitu tongkol (Auxis thazard), lemuru (Sardinella longiceps), cakalang (Katsuwonus pelamis), layang ( Decapterus russelli), layur (Trichiurus lepturus). Dalam kegiatan penangkapan, ketersediaan ikan sangat dipengaruhi oleh musim-musim penangkapan. Musim puncak terjadi pada bulan maret-agustus, musim biasa/sedang terjadi pada bulan SeptemberOktober, dan musim paceklik terjadi pada bulan Desember-Februari.

\section{Analisis Faktor-Faktor yang Mempengaruhi Hasil Produksi Pukat Cincin}

Analisis regresi faktor produksikoefisien determinasi $\left(\mathrm{R}^{2}\right)$ disajikan pada Tabel 4. Pada tabel R-Square sebesar 0,870 dari koefisien deerminasi yang dalam hal ini $87 \%$ variabel-variabel bebasnya dapat dijelaskan oleh variabel terikat. Diduga faktor-faktor lain misalna lingkungan atau kondisi daerah penangkpan ikan seperti cuaca, musim, dan keberdayaan sumberdaya.

Tingkat signifikan menggunakan $\alpha=$ $5 \%$. Dengan mengunakan selang kepercayaan 95\% diperoleh Fhitung sebesar 6.147 dan nilai Ftabel 3.49. Berdasarkan pengujian uji F, maka Ho di tolak karena nilai Fhitung $>$ Ftabel (6.147>3.49), artinya selang kepercayaan 95\% secara bersama sama faktor-faktor produksi unit penangkapan alat tangkap pukat cinci (Xi)

Tabel 4 Analisis regresi faktor produksi-koefisien determinasi $\left(\mathrm{R}^{2}\right)$

\begin{tabular}{|c|c|c|c|c|}
\hline \multicolumn{5}{|c|}{ Model Summary ${ }^{\mathrm{b}}$} \\
\hline Model & $\mathbf{R}$ & R Square & Adjusted R Sruare & Std. Error of the Estimate \\
\hline 1 & .934 & .870 & .730 & 767.199 \\
\hline
\end{tabular}

Uji F Tabel ANOVA

\begin{tabular}{lcccccc}
\hline Sumber & Db & Jumlah Kuadrat & $\begin{array}{c}\text { Rata-rata } \\
\text { Kuadrat }\end{array}$ & Fhit & F tabel & P \\
\hline Regresi & 4 & 3.506 & 8.576 & 6.147 & 3.49 & 0.000 \\
Residu & 15 & 2.894 & 7.526 & & & \\
\hline Total & 19 & 4.148 & & & \\
\hline
\end{tabular}


yang digunakan memiliki pengaruh nyata terhadap perubahan hasil produksi alat tangkap pukat cincin $(\mathrm{Y})$

Berdasarkan perhitungan nilai dari koefisien regresi (bi), dan sig. Fungsi produngsi alat tangkap pukat cincin di PPN Sibolga di dapatkan nilai Sig. Dari 10 faktor produksi di antaranya yaitu ukuran kapal (X1), daya mesni kapal (X2), panjang jaring (X3), tinggi jaring (X4), jumlah awak kapal (X5), BBM (X6), jumlah lampu (X7), jumlah es(X8), air tawar (X9), Perbekalan (X10) dengan $\alpha=5 \%$ selang kepercayaan 95\%. Nilai sig. Faktor-faktor produksi tersebut memiliki nilai lebuh kecil $(0,05)$, uji hipotesis t-student maka H0 ditolak, artinya dengan selang kepercayaan 95\% faktor produksi $(\mathrm{Xi})$ yang digunakan seccara parsial memilii peran nyata terhadap perubahan produksi (Y) pada unit penangkapan alat tangkap pukat cincin.

Variabel-vaiabel awak kapal (X5), BBM (X6), Jumlah Lampu (X7), Jumlah es (X8), air tawar (X9), perbekalan (X10) yang memiliki nilai sig $>\alpha(0,05)$, sedangkan persyaratan untuk lolos uji t-student nilai dari nilai sig $<\alpha$ $(0,05)$. Maka disimpulkan bahwa variabel awak kapal (X5), BBM (X6), Jumlah Lampu (X7), Jumlah es (X8), air tawar (X9), perbekalan (X10) tidak signifikan sehingga tidak dapat digunakan pada tahap selanjutnya.

Besar persentase variabel bebas (Xi) terhadap nilai variabel terikat (Y) diketahui dengan nilai determinasi (R2). Hasil perhitungan menggunakan analisis regresi fungsi Cobb-douglas diperoleh hasil nilai determinasi (R2) yaitu 0,870. Hal ini Xi yang digunakan dapat menjelaskan nilai $\mathrm{Y}$, yang artinya $87 \%$ variasi model produksi unit pnangkapan alat tangkap pukat cincin dapat dijelaskan dari ke empat variabel faktor-faktor produksi tersebut. Sehingga perubah tiap tiap variabel independen secara bersamaan sapat menyebabkan perubah nilai produksi unit penangkapan alat tangkap pukat cincin.

Model fungsi produksi yang digunakan dalam analisis faktor-faktor produksi yang mempengaruhi hasil produksi unit penangkapan alat tangkap pukat cincin adalah mode regresi berganda fungsi Cobbdouglas, berikut hasil pendugaan fungsi persamaan yang dihasilkan yaitu ;

$\operatorname{LnY}=-7.034 .574+21.254 \operatorname{LnX} 1+6.241 \operatorname{LnX} 2$ + 2.369 LnX3 + 54.410 LnX4

Keterangan :

$\ln \mathrm{Y}$ : Hasil tangkapan pukat cincin

ln X1 : Ukuran kapal

ln X2 : Daya mesin kapal

ln X3 : Panjang jaring

$\ln \mathrm{X} 4$ : Tinggi jaring

Nilai 21.254 $\ln \mathrm{X} 1$ dapat disimpulkan bahwa ukuran kapal di pengaruhi oleh langsung dengan produktifitas dan produksi tangkap. Hal ini di sebabkan b1 sebesar 21.254 yang di artikan bahwa setiap penambahan $1 \mathrm{GT}$ kapal akan meningkatkan hasil produksi alat

Tabel 5 Nilai t hit, dan SIG. Alat tangkap pukat cincin di PPN Sibolga

Uji t-student

\begin{tabular}{lcccc}
\hline Sumber & $\begin{array}{c}\text { Koefisien } \\
\text { Regresi }\end{array}$ & $\begin{array}{c}\text { Standar error } \\
\text { Coef }\end{array}$ & T hit & $\mathrm{P}$ \\
\hline Variabel & -7.034 .574 & & -4.237 & 0.001 \\
LnX1 & 21.254 & 0.271 & 2.539 & 0.023 \\
LnX2 & 6.241 & 0.440 & 2.750 & 0.015 \\
LnX3 & 2.369 & 0.560 & 3.391 & 0.004 \\
LnX4 & 54.410 & 0.336 & 3.051 & 0.008 \\
\hline
\end{tabular}

Sumber: Olahan Data Statistik, 2016

Keterangan : Tingkat Signifikan menggunakan $\alpha=5 \%(0,05), \mathrm{T}$ tabel $=2,131$ 
tangkap pukat cincin sebesar $21 \%$ per trip dengan asumsi variabel lainya bernilai tetap. Menurut Suryana dan DJPT (2013), bahwa semakin besar dimensi dimensi kapal maka kemampuan kapal tersebut untuk membawa pukat dan alat bantu penangkapan ikan lainnya semakin besar, dengan demikian jarak jangkau fishing ground akan semakin luas. Selai itu ukuran kapal berpengaruh juga terhadap pergerakan kapal tersebut dilaut seperti gerakan memutar.

Nilai 6.241 LnX2 dapat disimpulkan bahwa daya mesin kapal memberikan signifikan pengaruh terhadap jumlah hasil tangkapan ikan, kecepatan kapal dalam melakukan gerakan memutar ketika melingkari pukat pada saat operasi penangkapan tentunya sangat menentukan jumlah ikan yang dapat terperangkap dalam pukat sebelum lolos dari operasi penangkapan. Hal ini di sebabkan bi sebesar 6.241 yang di artikan bahwa penambhan 1 HP kapal akan meningkatkan hasil produksi alat tangkap pukat cincin sebesar 6\% pertrip dengan asumsi variabel lainnya berniali tetap. Menurut Wijopriono dan Genisa (2003), kapal dengan kecepatan yang relatif tinggi dapat menghalangi atau menyaini kecepatan ikan. Oleh karena itu, kapal yang bergerak relatif lebih cepat dari kecepatan renang ikan akan meningkatkan peluang tertangkapnya ikan. Kekuatan mesin yang besar, maka proses pelingkaran gerombolan ikan juga lebih cepat sehingga kemungkinan ikan untuk lolos jua semakin kecil. Jika prosess pelingkaran berlangsung lambat, maka kemungkinan ikan banyak yang lolos. Untuk itu, kecepatan menjadi faktor yang harus di pertimbangkan dalam melakukan penangkapan ikan menggunakan pukat cincin.

Nilai 2.369 LnX3 produksi alat tangkap pukat cincin di pengaruhi oleh panjang jaring dimana setiap pertambahan panjang 1 meter jaring dapat menghasilkan tangkapan sebesar 2\% per trip dengan asumsi variabel nya berniali tetap. Menurut Rizwan dan Aprilia (2011), semakin panjang alat tangkap pukat cincin maka luas, sehingga diharpkan ika yang berada dalam lingkarab tersebut semakib besar jumlahnya. Hasil penelitian menunjukkan bahwa panjang jaring yang digunkan dalan kegiatan operasional penangkapan pukat cincin Sibolga yaitu 500$1500 \mathrm{~m}$. Penetapan ukuran panjang jaring di tentukan oleh pemilik kapal/juraan darat. Perbedaan hasil tangkapan di akibatkan oleh fishing ground yang berbeda, ukuran alat tangkap dan kekuatan mesin yang digunakan unit penangkapan pukat cincin.

Nilai 54.410 LnX4 mempunyai arti bahwa tinggi jaring mempunyai pengaruh terhadap hasil tangkapan alat tangkap pukat cincin, dimana pertambahan $1 \mathrm{~m}$ dapat menghasilkan hasil tangkapan sebesar 54\% pertrip dengan asumsi variabel lainnya bernilai tetap. Semakin tinggi jaring semakin memperluas jangkauan dalan melakukan penangkapan ikan, menjerat ikan yang sudah berada di dalam jaring agar sulit keluar. Menurut Sudirman dan Mallawa (2004), tinggi/kedalaman pukat cincin harus di tentukan dengan memperhatikan perilaku dari ikan yang akan ditangkap dan kondisi perairan setempat. Minimum tinggi pukat cincin

\section{KESIMPULAN}

1. Keragaan teknis unit penangkapan pukat cincin antara lain ukuran panjang alat tangkap 140-160 m dengan bahan jaring PA (polyamide) kapal dengan ukuran 58-117 GT, jumlah nelayan 1220 orang. Alat bantu yang digunkan berupa lampu dengan 2 jenis yaitu lampu galaksi dan lampu neon. Pengoperasian selalu berpindah-pindah tempat, target tangkapan yaitu pelagis kecil dan pelagis besar.

2. Faktor-faktor yang berperan nyata pada unit penangkapan puat cincin di PPN Sibolga yaitu ukuran kapal (X1), daya mesin kapal (X3), panjang jaring (X3), tinggi jaring (X4). Faktor hubungan antara faktor-faktor dengan produksi alat tangkap pukat cincin di PPN Sibolga di presentasikan dalam model fungsi Cobb-Douglas, yaitu sebagai berikut :

$\operatorname{LnY}=-7.034 .574+21.254 \operatorname{LnX} 1+6.241$

LnX2 + 2.369 LnX3 + 54.410 LnX4 


\section{DAFTAR PUSTAKA}

Doll, Arazem. 1987. Production Economic Theory with Application. Columbus. Ohio (US): Gird Inc.

Kusaini. 2013. Pengaruh Faktor-faktor Produksi terhadap Hasil tangkapan ikan Nelayan Pukat cincin di Kabupaten Gorontalo Utara Provinsi Gorontalo. Jurnal Ilmiah Perikanan dan Kelautan. Vol 3 No. 1.

McCluske SM, Lewinson RL. 2008. Quantifying Fishing Effort: a synthesis ofcurrent methods and their applications. Fish and fisheries (9): 188-200.

Mukhtar. 2008. Faktor-faktor Produksi yang mempengaruhi produktivitas Kapal Purse seine. (Thesis). Program StudiAgribisnis Program Pascasarjana Universitas Haluoleo. Kendari. $60 \mathrm{hlm}$.

Rizwan, Setiawan I, dan Aprilia RM. 2011. Efeffect Of Production Factor On Purse Seine Fish Capture In The Lamulo Coastal Fisheris Port, Banda Aceh. Koordinator Kelautan Dan Perikanan Universitas Syiah Kuala, Banda Aceh. Jurnal Natural Vol. 11 (1). Hal : 24 -29.

Satria A. 2009. Ekologi Politik Nelayan. Bandung (ID): PT Lukis Pelangi Aksara.

Sudirman dan Mallawa. 2004. Teknik penangkapan ikan. Dinas Kelautan dan Perikanan, Statistik Perikanan Tangkap Provinsi Aceh, Banda Aceh (ID). Rineka Cipta. Jakarta

Suryana, S.A , Rahardjo, I.P Dan Sukandar. 2013. Pengaruh Panjang Jaring, Ukuran Kapal, Pk Mesin Dan Jumlah Abk Terhadap Produksi Ikan Pada Alat Tangkap Purse Seine Di Perairan Prigi Kabupaten Trenggalek - Jawa Timur. PSPK Student Journal. I (1); 36 - 43.

Wijopriono dan Genisa, 2003, Kajian Terhadap Laju Tangkap Dan Komposisi Hasil Tangkapan Purse Seine Mini Di Perairan Pantai Utara Jawa Tengah. Torani. Vol. 13 (1); 44-50. 